\title{
Elevated heart rate predicts $\beta$ cell function in non-diabetic individuals: the RISC cohort
}

\author{
Fabrice Bonnet ${ }^{1,2}$, Jean-Philippe Empana ${ }^{3}$, Andrea Natali ${ }^{4}$, Lucilla Monti ${ }^{5}$, \\ Alain Golay ${ }^{6}$, Katarina Lalic ${ }^{7}$, Jacqueline Dekker ${ }^{8}$, Andrea Mari ${ }^{9}$ and \\ Beverley Balkau ${ }^{2}$ on behalf of the RISC Study Group ${ }^{\dagger}$ \\ ${ }^{1}$ Service Endocrinologie-Diabétologie, CHU Rennes, Université Rennes 1, Rennes, France, \\ ${ }^{2}$ Inserm Centre for research in Epidemiology and Population Health (CESP) U1018, Villejuif, France, \\ ${ }^{3}$ Paris Cardiovascular Research Centre (PARCC), INSERM UMRS 970, Paris, France, ${ }^{4}$ Department of \\ Internal Medicine, University of Pisa, Pisa, Italy, ${ }^{5}$ Department of Internal Medicine, Cardio-Diabetes and \\ Core Lab, Diabetes Research Institute, IRCCS Ospedale San Raffaele, Milan, Italy, ${ }^{6}$ Service d'enseignement \\ thérapeutique pour maladies chroniques, Hôpitaux Universitaires de Genève, Geneva, Switzerland, \\ ${ }^{7}$ Faculty of Medicine University of Belgrade, Clinic for Endocrinology, Diabetes and Metabolic Diseases, \\ Belgrade, Serbia, ${ }^{8}$ Department of Epidemiology and Biostatistics, EMGO Institute for Health and \\ Care Research, Amsterdam, The Netherlands and ${ }^{9} \mathrm{C} N$ R Institute of Neuroscience, Padova, Italy \\ ${ }^{\dagger}$ (Information on the RISC Study and participating centres, RISC investigators, project management board and \\ Core Laboratories and reading centres can be found on http://www.egir.org/egirrisc/index.html)
}

Correspondence should be addressed to F Bonnet Email fabrice.bonnet@ chu-rennes.fr

\begin{abstract}
Context: Elevated heart rate has been associated with insulin resistance and incident type 2 diabetes but its relationship with $\beta$-cell function is not known. Our aim was to investigate whether baseline heart rate is associated with $\beta$-cell function and hyperglycaemia.

Methods: We used the prospective RISC cohort with 1005 non-diabetic individuals who had an oral glucose tolerance test (OGTT) at baseline and after 3 years. Impaired glucose regulation was defined as a fasting plasma glucose $\geq 6.1 \mathrm{mmol} / \mathrm{l}$ or a 2-h plasma glucose $\geq 7.8 \mathrm{mmol} / \mathrm{l}$. Insulin sensitivity was assessed by the OGIS index and insulin secretion and $\beta$-cell glucose sensitivity at both baseline and 3 years.

Results: Baseline heart rate was positively related to both fasting $(P<0.0001)$ and $2 \mathrm{~h}$ glucose levels $(P=0.02)$ at year 3 and predicted the presence of impaired glucose regulation at year 3 in a logistic regression model adjusting for insulin sensitivity at inclusion (OR/10 beats per min: $1.31 ; 95 \% \mathrm{Cl}(1.07-1.61) ; P=0.01)$. Baseline heart rate was associated with lower insulin sensitivity $(\beta=-0.11 ; P<.0001)$, a decrease in both $\beta$-cell glucose sensitivity $(\beta=-0.11 ; P=0.003)$ and basal insulin secretion rate $(\beta=-0.11 ; P=0.002)$ at 3 years in an adjusted multivariable regression model. Baseline heart rate predicted the 3 -year decrease in $\beta$-cell glucose sensitivity $(\beta=-0.10 ; P=0.007)$ and basal insulin secretion $(\beta=-0.12 ; P=0.007)$.

Conclusions: Heart rate predicts $\beta$-cell function and impaired glucose regulation at 3 years in non-diabetic individuals, independently of the level of insulin sensitivity. These findings suggest a possible effect of the sympathetic nervous system on $\beta$-cell dysfunction, which deserves further investigation.
\end{abstract}

\section{Introduction}

Identification of factors predictive of $\beta$-cell failure is important for both prevention and treatment of type 2 diabetes. Elevated heart rate has been associated with an increased risk of type 2 diabetes in a number of epidemiological studies $(1,2,3,4,5)$. This association has been mainly attributed to increased insulin resistance, secondary to the activation of sympathetic nerve activity $(6,7,8)$. However, only one small longitudinal study $(7)$
(C) 2015 European Society of Endocrinology Printed in Great Britain
Published by Bioscientifica Ltd. 
has assessed the predictive value of sympathetic activity on the development of insulin resistance and fasting hyperglycaemia, using surrogate measures of insulin sensitivity. In addition, the relationship between heart rate and $\beta$-cell function, a crucial player in glucose tolerance, has not been fully investigated so far. The mechanisms behind the increased heart rate and glucose intolerance association remain to be elucidated.

The aim of this analysis is to assess whether elevated heart rate predicts altered $\beta$-cell function after accounting for insulin resistance, over a 3-year follow-up in a cohort of non-diabetic subjects and to study whether this explains the association between heart rate and impaired glucose regulation (fasting plasma glucose $\geq 6.1 \mathrm{mmol} / \mathrm{l}$ or 2 -h plasma glucose (following a 75 -g OGTT) $\geq 7.8 \mathrm{mmol} / \mathrm{l}$ ). We use the Relationship between Insulin Sensitivity and Cardiovascular disease (RISC) study which presents a well characterized cohort of about 1000 people with a baseline measure of clamp-based insulin sensitivity. At both baseline and after 3 years of follow-up, estimates of insulin secretion and $\beta$-cell function as well as model estimates of insulin resistance are discussed. In addition, we examine whether the association between heart rate and $\beta$-cell function is influenced by baseline leptin and non-esterified fatty acids (NEFA) concentrations, as these parameters have been reported to correlate with heart rate and sympathetic nervous activity (9).

\section{Subjects and methods}

\section{Study population}

RISC is a prospective observational cohort study whose rationale and methodology have been published, as well as the characteristics of the individuals recruited $(10,11,12)$. Ethics Committee approval was obtained by each recruiting centre. Volunteers were given detailed written information on the study as well as an oral explanation, and they all signed a consent form.

Briefly, clinically healthy men and women, aged 3060 years, were recruited from the local populations of 19 centres in 14 European countries. Initial exclusion criteria were treatment for hypertension, lipid disorders or diabetes, pregnancy, cardiovascular or chronic lung disease, weight change $\geq 5 \mathrm{~kg}$ in the last 6 months, cancer in the last 5 years and renal failure. Additional exclusion criteria were blood pressure $\geq 140 / 90 \mathrm{mmHg}$, fasting plasma glucose $\geq 7.0 \mathrm{mmol} / \mathrm{l}$, 2-h plasma glucose (following a 75-g OGTT) $\geq 11.0 \mathrm{mmol} / \mathrm{l}$.

We study 1005 healthy individuals (461 men and 544 women) who had an evaluation of both $\beta$-cell function and insulin sensitivity at baseline and who had complete data at the 3 year follow up (13). No participant included was taking antihypertensive or beta-blocker medications at baseline.

\section{Methods}

Height, body weight, and BMI were recorded and fat mass were evaluated by the TANITA bioimpedance balance (Tanita International Division, Tokyo, Japan). Smoking was assessed from a questionnaire (14). Information on physical activity was collected with the 7-day International Physical Activity Questionnaire (IPAQ), a previously validated assessment tool for international studies that evaluates daily physical activity habits (15).

Blood samples were taken at fasting and at 30, 60, 90 and $120 \mathrm{~min}$ into the OGTT for central analysis of routine blood chemistry. Blood collected during the studies was separated into plasma and serum, aliquoted and stored at $-20^{\circ} \mathrm{C}$ for determination of glucose, insulin and C-peptide levels and $-80^{\circ} \mathrm{C}$ for lipids in central laboratories.

Glucose concentrations were measured by the glucose oxidase technique. Plasma insulin and C-peptide were measured by a two-site time-resolved fluoroimmunoassay (AutoDELFIA Insulin kit; Wallac Oy, Turku, Finland) using monoclonal antibodies, with the following assay characteristics (for insulin and C-peptide, respectively): sensitivity $1-2$ and $5 \mathrm{pmol} / \mathrm{l}$, within-assay variation $5 \%$ and between-assay variation $3.5 \%$. Insulin area under the time-concentration curve was calculated using the trapezium rule.

Serum leptin was determined by an in-house timeresolved DELFIA assay on an AutoDELFIA autoanalyser in Cambridge, UK. Measurement of plasma NEFA concentrations was carried out using Randox enzymatic kit (Hitachi Modular P unit). The CV was $<5 \%$.

On a separate day within 1 month of the OGTT, a hyperinsulinemic-euglycaemic clamp was performed to estimate insulin sensitivity. Details on the clamp procedure have been described (16). Insulin sensitivity was quantified by the glucose infused over the last $40 \mathrm{~min}$ of the clamp (normalised by fat free mass), divided by the mean plasma insulin concentration over the same period, M/I.

Insulin sensitivity at both baseline and at year 3 was estimated with the oral glucose insulin sensitivity (OGIS) method, which has been validated against the insulin clamp technique (17).

$\beta$-cell function was assessed from the OGTT using a model describing the relationship between insulin 
secretion (calculated from C-peptide concentrations with the method of Van Cauter et al. (18)) and glucose concentrations $(12,16)$. Basal and total (integral during the OGTT) insulin secretion rates were determined using the model. For all statistical analyses, we used the product of either basal or total insulin secretion with the OGIS insulin sensitivity index to express the rate of insulin secretion, in relation with the concomitant degree of insulin resistance.

$\beta$-cell glucose sensitivity is the mean slope of the $\beta$-cell dose response in the observed glucose range. This parameter measures the sensitivity of the $\beta$-cell to the glucose changes and is expressed in $\mathrm{pmol} / \mathrm{min}$ per $\mathrm{m}^{2}$ per $\mathrm{mM}$ (12).

Heart rate and blood pressure were measured in triplicate after $5 \mathrm{~min}$ of rest by trained study nurses using an OMRON 705CP (Omron Healthcare GmbH, Hamburg, Germany) with participants sitting according to a standard protocol. The median of these readings is used in the analysis.

Impaired fasting glucose is defined by a fasting plasma glucose $\geq 6.1 \mathrm{mmol} / \mathrm{l}$, impaired glucose tolerance by a 2 -h plasma glucose (following a 75-g OGTT) $\geq 7.8 \mathrm{mmol} / \mathrm{l}$, and impaired glucose regulation by either or both of these conditions.

\section{Statistical analysis}

Data are expressed as mean \pm s.D. or as median (interquartile range) for variables with a skewed distribution and categorical data as percentages. Variables that were not symmetrically distributed were $\log$ transformed before analyses. Baseline characteristics, means and percentages were compared using ANOVA and $\chi^{2}$ tests respectively, according to quartile groups of baseline resting heart rate. A trend test was also used and a Mann-Whitney's test to compare values in quartile groups. Changes in metabolic variables over the 3 years (expressed as \% from the respective baseline value) according to the quartile groups of heart rate at baseline were compared with a Kruskal-Wallis's test.

Multivariable linear regression analyses were used to assess the association between heart rate at baseline and glucose, insulin sensitivity, and $\beta$-cell function at year 3 , as well as with changes in these metabolic parameters (the difference between the values at baseline and year 3 , divided by the respective baseline value). There were no deviations from linearity for these relations with heart rate as tested by spline analysis. Multivariable logistic regression analysis was used to analyse associations between heart rate and impaired glucose regulation at year 3 . An interaction between baseline heart rate and insulin sensitivity was tested, and also adjustments by baseline leptin and NEFA. All multivariable analyses adjusted for age, gender, recruitment centre, physical activity (expressed as the number of Mets of all activity), smoking, waist, the $M / I$ value at baseline and weight gain over the follow-up. We have not adjusted on baseline values of these variables but studied changes as recommended in the epidemiological literature (19).

Changes in metabolic variables over the 3 years (expressed as \% change from the respective baseline value) according to the quartiles of heart rate at baseline were compared with a Kruskal-Wallis's test. Paired values (year 0 and year 3 ) were compared using the Wilcoxon's test.

Statistical analyses used StatView (version 5.0, SAS Institute, Inc., Cary, NC, USA) and SAS version 9.2 (SAS Institute).

\section{Results}

\section{Metabolic characteristics associated with heart rate at} baseline

Age, BMI, waist circumference and fasting glycaemia did not differ across the quartile groups of baseline heart rate, whereas the $2 \mathrm{~h}$ glucose concentrations increased with increasing heart rate (Table 1). As a consequence, the prevalence of impaired glucose tolerance at baseline increased across the quartiles of heart rate (Table 1).

A higher heart rate was positively associated with greater physical inactivity, higher plasma concentrations of leptin and fasting NEFA, and enhanced insulin resistance (as reflected by lower M/I and OGIS values) (Table 1).

\section{Heart rate at baseline and impaired glucose regulation at year 3}

In multivariable regression, heart rate at baseline, as a continuous variable, was significantly related to fasting $(P=0.003)$ but not 2 -h glucose levels $(P=0.24)$ at year 3 , after controlling for age, sex, recruitment centre, physical activity, smoking, waist circumference, insulin sensitivity at baseline, changes in body weight during the follow-up.

At year 3, 193 participants had impaired glucose regulation. Baseline heart rate, as a continuous value, significantly predicted the presence of impaired glucose regulation at year 3 in a logistic regression model after controlling for age, sex, recruitment centre, physical activity, smoking, waist circumference, insulin sensitivity at baseline and changes in body weight over the follow-up (OR per increase of 10 beats/min: 1.31; 95\% CI (1.07-1.61); $P=0.01)$. The increased risk of impaired glucose regulation associated with elevated resting heart rate was independent of the level of clamp-based insulin sensitivity at baseline 
Table 1 Baseline characteristics of the RISC cohort according to quartiles groups of heart rate at baseline, the RISC study. Data shown are mean \pm s.D., median (interquartile range) or $\%$ and $P$ values from ANOVA and $\chi^{2}$ tests.

\begin{tabular}{|c|c|c|c|c|c|}
\hline & \multicolumn{4}{|c|}{ Groups defined by quartiles of baseline heart rate } & \multirow[b]{2}{*}{$\boldsymbol{P}$} \\
\hline & $1(n=249)$ & $2(n=248)$ & $3(n=254)$ & $4(n=254)$ & \\
\hline Heart rate (beats/min) & $56 \pm 4$ & $64 \pm 2$ & $71 \pm 2$ & $82 \pm 6$ & \\
\hline Age (years) & $44.5 \pm 8.3$ & $44.7 \pm 8.0$ & $44.9 \pm 8.4$ & $43.2 \pm 8.4$ & 0.09 \\
\hline Waist (cm) & $87 \pm 12$ & $87 \pm 12$ & $87 \pm 13$ & $88 \pm 13$ & 0.64 \\
\hline BMI $\left(\mathrm{kg} / \mathrm{m}^{2}\right)$ & $25.1 \pm 3.4$ & $25.6 \pm 3.9$ & $25.3 \pm 4.0$ & $25.8 \pm 4.4$ & 0.27 \\
\hline Fat mass $(\mathrm{kg})$ & $18.7 \pm 7.9$ & $21.2 \pm 8.9$ & $20.6 \pm 8.7$ & $22.5 \pm 8.9$ & $<0.0001$ \\
\hline Men $(\%)$ & 66.5 & 38.3 & 45.3 & 31.4 & $<0.0001$ \\
\hline Smoker $(\%)$ & 23.3 & 23.2 & 26.2 & 30.9 & 0.18 \\
\hline Physically inactive (\%) & 14.0 & 19.7 & 22.1 & 23.7 & 0.07 \\
\hline Mets of all activity (mets/day) & $2705(3472)$ & $2226(3724)$ & $2140(3792)$ & $1715(3385)$ & 0.001 \\
\hline Systolic blood pressure (mmHg) & $118 \pm 12$ & $117 \pm 13$ & $118 \pm 13$ & $118 \pm 12$ & 0.90 \\
\hline Diastolic blood pressure $(\mathrm{mmHg})$ & $73 \pm 8$ & $74 \pm 8$ & $74 \pm 8$ & $76 \pm 7$ & 0.0001 \\
\hline Leptin $(\mathrm{ng} / \mathrm{ml})^{\mathrm{a}}$ & $5.5(8.7)$ & $10.5(12.6)$ & $8.2(14.0)$ & $12.4(14.8)$ & $<0.0001$ \\
\hline Fasting NEFA $(\mathrm{mmol} / \mathrm{l})^{a}$ & $0.44(0.2)$ & $0.49(0.2)$ & $0.47(0.3)$ & $0.54(0.3)$ & $<0.0001$ \\
\hline Fasting glucose $(\mathrm{mmol} / \mathrm{l})$ & $5.1 \pm 0.5$ & $5.1 \pm 0.5$ & $5.1 \pm 0.5$ & $5.1 \pm 0.6$ & 0.76 \\
\hline Impaired fasting glucose (\%) & 3.6 & 4.5 & 3.2 & 3.9 & 0.80 \\
\hline 2 -h glucose $(\mathrm{mmol} / \mathrm{l})$ & $5.4 \pm 1.4$ & $5.7 \pm 1.5$ & $5.8 \pm 1.5$ & $6.1 \pm 1.8$ & $<0.0001$ \\
\hline Impaired glucose tolerance (\%) & 6.0 & 8.6 & 10.3 & 15.0 & 0.007 \\
\hline Fasting insulin $(\mathrm{pmol} / \mathrm{l})^{\mathrm{a}}$ & $24.0(18.0)$ & $30.0(20.0)$ & $32.0(25.0)$ & $36.0(25.2)$ & $<0.0001$ \\
\hline $\begin{array}{l}\text { Clamp Insulin Sensitivity }(\mathrm{M} / \mathrm{I})^{\mathrm{a}} \\
(\mu \mathrm{mol} / \mathrm{min} \text { per kg FFM per nM) }\end{array}$ & $135(89)$ & $130(88)$ & $133(90)$ & $127(79)$ & 0.01 \\
\hline OGIS insulin sensitivity $\left(\mathrm{ml} / \mathrm{min}\right.$ per $\left.\mathrm{m}^{2}\right)$ & $448.2 \pm 57.7$ & $443.4 \pm 53.2$ & $439.4 \pm 63.1$ & $433.9 \pm 67.9$ & 0.02 \\
\hline $\begin{array}{l}\beta \text {-cell glucose sensitivity }{ }^{a}(\mathrm{pmol} / \mathrm{min} \\
\text { per } \mathrm{m}^{2} \text { per } \mathrm{mM} \text { ) }\end{array}$ & $109(80)$ & $117(85)$ & $111(70)$ & $111(78)$ & 0.92 \\
\hline $\begin{array}{l}\text { Basal insulin secretion } \text { rate }^{\mathrm{b}} \times \\
\text { OGIS index }\end{array}$ & $29.2(11.1)$ & $31.9(14.5)$ & $30.9(13.2)$ & $31.8(13.7)$ & 0.01 \\
\hline Total insulin secretion ${ }^{b} \times$ OGIS index $^{a}$ & $16.4(5.7)$ & $17.0(6.1)$ & $17.7(5.9)$ & $18.4(5.9)$ & 0.003 \\
\hline
\end{tabular}

aLog-transformed for analysis.

${ }^{\mathrm{b}}$ Total and basal insulin secretion during the OGTT are both expressed in relation to the OGIS insulin sensitivity index and multiplied by $10^{-3}$ for simplification of presentation.

(Fig. 1). Additional adjustment for leptin or for NEFA in this model did not alter the significant associations.

\section{Heart rate and insulin resistance at year 3}

Baseline heart rate was associated with greater insulin resistance at year 3. In univariate analysis, the OGIS insulin sensitivity index at year 3 was higher for those with baseline heart rate below the first quartile as compared to those with heart rate above the last quartile $(441.0 \pm 82.8$ vs $422.9 \pm 64.9 \mathrm{ml} / \mathrm{min}$ per $\left.\mathrm{m}^{2}, P=0.007\right)$.

In a multivariable linear regression model, baseline heart rate was negatively related to insulin sensitivity at year $3(\beta=-0.11, P=0.0001)$.

\section{Heart rate and $\beta$-cell function at year 3}

Heart rate at baseline, considered as a continuous value, was significantly and inversely associated with both basal insulin secretion rate $(\beta=-0.11, P=0.002)$ and $\beta$-cell glucose sensitivity $(\beta=-0.11, P=0.003)$ at follow-up in a multivariable regression analysis after adjustment for baseline age, sex, recruitment centre, physical activity, smoking, waist circumference and changes in body weight over the follow-up. Heart rate was also inversely related to total insulin secretion rate at year 3 but the relationship was not significant $(\beta=-0.07, P=0.94)$.

Further adjustment for baseline leptin or for NEFA concentrations or fat mass did not modify the inverse association between heart rate and either $\beta$-cell glucose sensitivity or basal insulin secretion at year 3 .

\section{Heart rate and changes in $\beta$-cell function over the follow-up}

A heart rate above the third quartile at baseline ( $\geq 75$ beats/min) was significantly related to a decrease in $\beta$-cell glucose sensitivity, basal and total insulin secretion rate over 3 years (Table 2). $\beta$-cell glucose sensitivity declined for those with a heart rate above the median at baseline, but this was significant only for those above the third quartile (Fig. 2). 


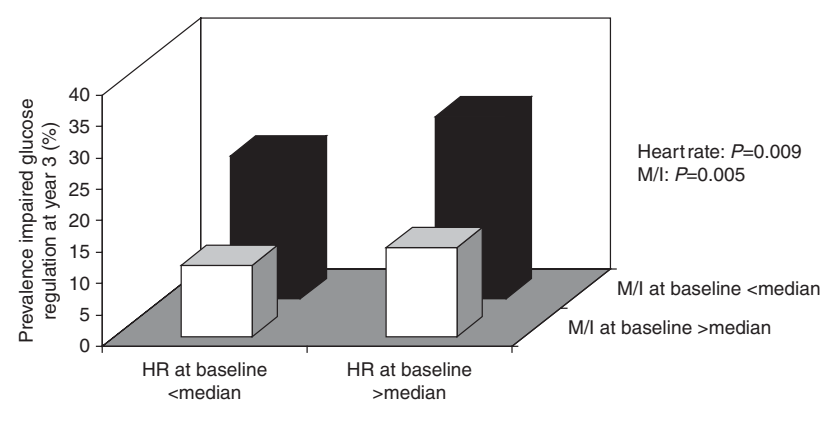

Figure 1

Prevalence of impaired glucose regulation (impaired fasting plasma glucose and/or impaired glucose tolerance) at year 3 according to both heart rate (HR) and insulin sensitivity (M/l) at baseline. $P$ value adjusted for age, sex, recruitment centre, physical activity, smoking, waist circumference and changes in body weight over the follow-up.

There was also an inverse relationship between baseline heart rate and the changes in both $\beta$-cell glucose sensitivity $(P=0.007)$ and basal insulin secretion rate $(P=0.007)$ when heart rate was considered as a continuous value, in a multiple linear regression, after adjustment for baseline age, sex, recruitment centre, physical activity, smoking, waist circumference and changes in body weight over the follow-up.

\section{Discussion}

The novel findings of this study are that elevated heart rate at baseline is associated with $\beta$-cell function and impaired glucose regulation at year 3 in healthy non-diabetic individuals, independently of the level of insulin sensitivity. These results are in keeping with previous evidence showing that heart rate is predictive of type 2 diabetes in the general population $(2,3,4,5,20)$. However, the precise nature of the pathophysiological relationship underlying the increased risk of hyperglycaemia in those with an elevated heart rate has not been explained. Resting heart rate is a marker of the autonomic nervous system, with elevated heart rate reflecting a shift in autonomic balance toward enhanced sympathetic nervous activity and reduced vagal tone (21). Some evidence suggests that sympathetic activation contributes to the development of insulin resistance in humans $(7,8,22,23)$. A pilot study showed that 3 months after renal denervation, fasting glucose concentrations were reduced in patients with resistant hypertension, suggesting that the sympathetic nervous system may directly modulate the glucose metabolism (24). An inverse relationship between heart rate and insulin sensitivity, as assessed by an intravenous glucose tolerance test, was reported in the IRAS cohort (23). Furthermore, a recent study demonstrated that pharmacological blockade of the sympathetic system improved insulin sensitivity in obese insulin-resistant patients, which supports a direct influence of the autonomic nervous system on insulinmediated glucose utilization in humans (25).

Our observation that baseline heart rate is positively associated with the basal insulin secretion rate at year 3 is in keeping with findings from cross-sectional studies showing a positive association between heart rate and either first-phase insulin secretion (23) and insulin response to oral glucose (26). We speculate that this is probably related, at least in part, to both the enhanced insulin resistance and the increase in plasma glucose associated with elevated heart rate, that stimulates insulin secretion, as a physiological compensation (16).

To the best of our knowledge, there is no previously published data on the nature of the longitudinal relationship between heart rate and $\beta$-cell function. Impaired $\beta$-cell glucose responsiveness has been demonstrated to be a key determinant of the changes in glucose tolerance in healthy individuals $(12,16)$. Therefore, our findings suggest that altered $\beta$-cell function may contribute to explain the predictive value of elevated heart rate for the risk of diabetes beyond insulin resistance.

Table 2 Changes in $\beta$-cell function over 3 years according to heart rate at baseline, the RISC study. Changes in the variables are expressed as \% from the respective baseline values. Data shown are median (interquartile range). $P$ value from a Kruskal-Wallis's test.

\begin{tabular}{|c|c|c|c|c|c|}
\hline & \multicolumn{4}{|c|}{ Groups defined by quartiles of baseline heart rate } & \multirow[b]{2}{*}{$\boldsymbol{P}$} \\
\hline & $1(n=249)$ & $2(n=248)$ & $3(n=254)$ & $4(n=254)$ & \\
\hline $\begin{array}{l}\beta \text {-cell glucose sensitivity }\left(\mathrm{pmol} / \mathrm{min} \text { per } \mathrm{m}^{2} \text { per } \mathrm{mM}\right) \\
\text { Basal insulin secretion } \text { rate }^{\mathrm{a}} \times \text { OGIS index } \\
\text { Total insulin secretion }^{\mathrm{a}} \times \text { OGIS index }\end{array}$ & $\begin{array}{l}0.3(74.6) \\
0.8(1.5) \\
4.3(31.1)\end{array}$ & $\begin{array}{l}0.5(74.1) \\
0.5(1.4) \\
2.8(25.5)\end{array}$ & $\begin{array}{l}0.5(75.7) \\
0.5(1.7) \\
3.2(30.6)\end{array}$ & $\begin{aligned}-9.3(68.9) \\
0.4(1.2) \\
-3.2(30.4)\end{aligned}$ & $\begin{array}{l}0.028 \\
0.0003 \\
0.008\end{array}$ \\
\hline
\end{tabular}

${ }^{a}$ Total and basal insulin secretion during the OGTT are both expressed in relation to the OGIS insulin sensitivity index and multiplied by $10^{-3}$ for simplification of presentation. 


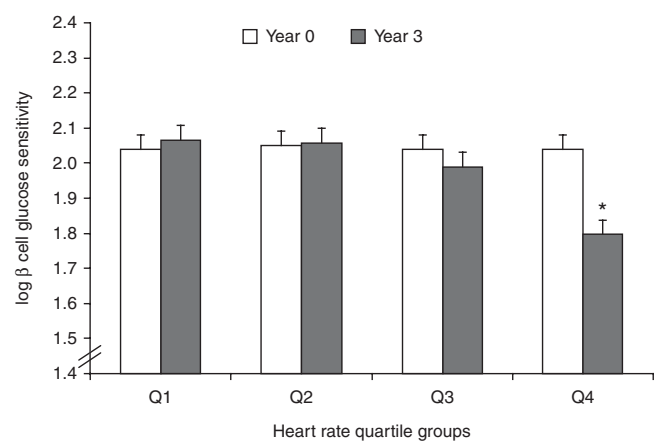

\section{Figure 2}

$\beta$-cell glucose sensitivity (mean \pm S.E.M.) in year 0 and year 3 according to quartile groups of heart rate at baseline. ${ }^{*} P<0.05$ for those above the third quartile, comparing baseline and year 3 by a paired test.

The association between elevated heart rate and $\beta$-cell function could reflect the effect of the sympathetic nervous system. Islet innervation of adrenergic nerves has been documented for many years (27). A body of evidence in both animals and humans has demonstrated that sympathetic stimulation induces an inhibition of basal and glucose-stimulated insulin secretion $(28,29,30)$. The net effect of noradrenaline on insulin secretion might depend on the relative abundance or activity of $\alpha$-adrenoceptors compared with $\beta$-adrenoceptors on the $\beta$-cells (29). However, the impact of stimulation of the sympathetic nerve system on the sensitivity of the $\beta$-cell to glucose is still not known.

Tight interactions between leptin, the sympathetic nervous system activity and heart rate have been reported (31). However, the fact that our results remain unchanged after taking concentrations of leptin into account argues against a potential confounding contribution of leptin in the association. Furthermore, the concentration of free fatty acids, which is associated with heart rate, does not explain the relation between heart rate and $\beta$-cell glucose sensitivity.

Early stage $\beta$-cell dysfunction has been characterized in the non-diabetic RISC population by impaired $\beta$-cell glucose sensitivity, a feature associated with heart rate in the present study (16). Therefore, our findings suggest that elevated heart rate may help to identify the individuals who are at risk of impaired $\beta$-cell function beyond the presence of conventional metabolic risk factors. Further investigations are needed to confirm this concept.

Limitations of the present study include the absence of ambulatory heart rate assessment and recording baseline resting heart rate on only one occasion as has often been the case in previous epidemiological studies. Furthermore, we did not specifically assess the degree of physical fitness which may affect heart rate. We also did not detect undiagnosed obstructive sleep apnea that might have an impact on heart rate and sympathetic activity. The euglycemic clamp was performed only at baseline and the estimation of the changes in insulin sensibility over the follow-up was done with the OGIS index.

The strengths of the study are the large RISC cohort of healthy subjects, the assessment of $\beta$-cell function and insulin sensitivity at baseline and at 3 years with centralized laboratory assays and the measurement of leptin concentrations.

In conclusion, our study shows that in non-diabetic individual, elevated heart rate predicts a decrease in $\beta$-cell glucose sensitivity and a reduction in basal insulin secretion rate over the follow-up, suggesting a novel mechanism underlying the association between elevated heart rate and the risk of diabetes. These findings also suggest a possible effect of the sympathetic nervous system on $\beta$-cell function, which deserves further investigation.

\section{Declaration of interest}

The authors declare that there is no conflict of interest that could be perceived as prejudicing the impartiality of the research reported.

\section{Funding}

The RISC Study was supported by EU grant number QLG1-CT-2001-01252, with additional support from AstraZeneca (Sweden).

\section{Author contribution statement}

The list of RISC investigators is presented in the ESM. F Bonnet was responsible for the conception of the study, analysis of data, and wrote the manuscript. B Balkau analysed data and revised the manuscript. A Mari contributed to the writing of the manuscript and revised it. J-P Empana, A Natali, L Monti, A Golay, K Lalic and J M Dekker contributed to the analysis and interpretation of the data and revised the manuscript critically. All authors approved the final version.

\section{References}

1 Carnethon MR, Golden SH, Folsom AR, Haskell W \& Liao D. Prospective investigation of autonomic nervous system function and the development of type 2 diabetes: the Atherosclerosis Risk In Communities study, 1987-1998. Circulation 2003107 2190-2195. (doi:10.1161/01.CIR. 0000066324.74807.95)

2 Carnethon MR, Yan L, Greenland P, Garside DB, Dyer AR, Metzger B \& Daviglus ML. Resting heart rate in middle age and diabetes development in older age. Diabetes Care 200831 335-339. (doi:10.2337/dc07-0874) 
3 Shigetoh Y, Adachi H, Yamagishi S, Enomoto M, Fukami A, Otsuka M, Kumagae S, Furuki K, Nanjo Y \& Imaizumi T. Higher heart rate may predispose to obesity and diabetes mellitus: 20 -year prospective study in a general population. American Journal of Hypertension 200922 151-155. (doi:10.1038/ajh.2008.331)

4 Zhang X, Shu XO, Xiang YB, Yang G, Li H, Cai H, Gao YT \& Zheng W. Resting heart rate and risk of type 2 diabetes in women. International Journal of Epidemiology 201039 900-906. (doi:10.1093/ije/dyq068)

5 Bemelmans RH, Wassink AM, van der Graaf Y, Nathoe HM, Vernooij JW, Spiering W \& Visseren FL. Risk of elevated resting heart rate on the development of type 2 diabetes in patients with clinically manifest vascular diseases. European Journal of Endocrinology/ European Federation of Endocrine Societies 2012166 717-725. (doi:10.1530/EJE-11-1017)

6 Deibert DC \& DeFronzo RA. Epinephrine-induced insulin resistance in man. Journal of Clinical Investigation 198065 717-721. (doi:10.1172/ JCI109718)

7 Flaa A, Aksnes TA, Kjeldsen SE, Eide I \& Rostrup M. Increased sympathetic reactivity may predict insulin resistance: an 18-year follow-up study. Metabolism 200857 1422-1427. (doi:10.1016/ j.metabol.2008.05.012)

8 Lembo G, Capaldo B, Rendina V, Iaccarino G, Napoli R, Guida R, Trimarco B \& Sacca L. Acute noradrenergic activation induces insulin resistance in human skeletal muscle. American Journal of Physiology 1994 266 E242-E247.

9 Narkiewicz K, Somers VK, Mos L, Kato M, Accurso V \& Palatini P. An independent relationship between plasma leptin and heart rate in untreated patients with essential hypertension. Journal of Hypertension 199917 245-249. (doi:10.1097/00004872-199917020-00009)

10 Hills SA, Balkau B, Coppack SW, Dekker JM, Mari A, Natali A, Walker M \& Ferrannini E. The EGIR-RISC STUDY (The European group for the study of insulin resistance: relationship between insulin sensitivity and cardiovascular disease risk): I. Methodology and objectives. Diabetologia 200447 566-570. (doi:10.1007/s00125-004-1335-5)

11 Bonnet F, Patel S, Laville M, Balkau B, Favuzzi A, Monti LD, Lalic N \& Walker M. Influence of the ACE gene insertion/deletion polymorphism on insulin sensitivity and impaired glucose tolerance in healthy subjects. Diabetes Care 200831 789-794. (doi:10.2337/ dc07-1788)

12 Mari A, Tura A, Natali A, Laville M, Laakso M, Gabriel R, Beck-Nielsen H $\&$ Ferrannini E. Impaired $\beta$ cell glucose sensitivity rather than inadequate compensation for insulin resistance is the dominant defect in glucose intolerance. Diabetologia 201053 749-756. (doi:10.1007/ s00125-009-1647-6)

13 Pataky Z, Golay A, Laville M, Disse E, Mitrakou A, Guidone C, Gabriel R $\&$ Bobbioni-Harsch E. Fasting insulin at baseline influences the number of cardiometabolic risk factors and R-R interval at 3 years in a healthy population: the RISC study. Diabetes \& Metabolism 201339 330-336. (doi:10.1016/j.diabet.2013.05.008)

14 Bonnet F, Ducluzeau PH, Gastaldelli A, Laville M, Anderwald CH, Konrad T, Mari A \& Balkau B. Liver enzymes are associated with hepatic insulin resistance, insulin secretion, and glucagon concentration in healthy men and women. Diabetes 201160 1660-1667. (doi:10.2337/ db10-1806)

15 Craig CL, Marshall AL, Sjostrom M, Bauman AE, Booth ML, Ainsworth BE, Pratt M, Ekelund U, Yngve A, Sallis JF et al. International physical activity questionnaire: 12-country reliability and validity. Medicine and Science in Sports and Exercise 200335 1381-1395. (doi:10.1249/01.MSS.0000078924.61453.FB)
16 Ferrannini E, Natali A, Muscelli E, Nilsson PM, Golay A, Laakso M, BeckNielsen $\mathrm{H} \&$ Mari A. Natural history and physiological determinants of changes in glucose tolerance in a non-diabetic population: the RISC study. Diabetologia 201154 1507-1516. (doi:10.1007/s00125-0112112-x)

17 Mari A, Pacini G, Murphy E, Ludvik B \& Nolan JJ. A model-based method for assessing insulin sensitivity from the oral glucose tolerance test. Diabetes Care 200124 539-548. (doi:10.2337/diacare.24.3.539)

18 Van Cauter E, Mestrez F, Sturis J \& Polonsky KS. Estimation of insulin secretion rates from C-peptide levels. Comparison of individual and standard kinetic parameters for C-peptide clearance. Diabetes 199241 368-377. (doi:10.2337/diabetes.41.3.368)

19 Glymour MM, Weuve J, Berkman LF, Kawachi I \& Robins JM. When is baseline adjustment useful in analyses of change? An example with education and cognitive change American Journal of Epidemiology 2005 162 267-278. (doi:10.1093/aje/kwi187)

20 Carnethon MR, Prineas RJ, Temprosa M, Zhang ZM, Uwaifo G \& Molitch ME. The association among autonomic nervous system function, incident diabetes, and intervention arm in the Diabetes Prevention Program. Diabetes Care 200629 914-919. (doi:10.2337/ diacare.29.04.06.dc05-1729)

21 Grassi G, Vailati S, Bertinieri G, Seravalle G, Stella ML, Dell'Oro R \& Mancia G. Heart rate as marker of sympathetic activity. Journal of Hypertension 199816 1635-1639. (doi:10.1097/00004872-19981611000010)

22 Jamerson KA, Julius S, Gudbrandsson T, Andersson O \& Brant DO. Reflex sympathetic activation induces acute insulin resistance in the human forearm. Hypertension 199321 618-623. (doi:10.1161/01.HYP.21.5.618)

23 Festa A, D'Agostino R Jr, Hales CN, Mykkanen L \& Haffner SM. Heart rate in relation to insulin sensitivity and insulin secretion in nondiabetic subjects. Diabetes Care 200023 624-628. (doi:10.2337/ diacare.23.5.624)

24 Mahfoud F, Schlaich M, Kindermann I, Ukena C, Cremers B, Brandt MC, Hoppe UC, Vonend O, Rump LC, Sobotka PA et al. Effect of renal sympathetic denervation on glucose metabolism in patients with resistant hypertension: a pilot study. Circulation 2011 123 1940-1946. (doi:10.1161/CIRCULATIONAHA.110.991869)

25 Gamboa A, Okamoto LE, Arnold AC, Figueroa RA, Diedrich A, Raj SR, Paranjape SY, Farley G, Abumrad N \& Biaggioni I. Autonomic Blockade Improves Insulin Sensitivity in Obese Subjects. Hypertension 201464 867-874. (doi:10.1161/HYPERTENSIONAHA.114.03738)

26 Facchini FS, Stoohs RA \& Reaven GM. Enhanced sympathetic nervous system activity. The linchpin between insulin resistance, hyperinsulinemia, and heart rate. American Journal of Hypertension 1996 9 1013-1017. (doi:10.1016/0895-7061(96)87747-8)

27 Robertson RP \& Porte D Jr. Adrenergic modulation of basal insulin secretion in man. Diabetes 197322 1-8. (doi:10.2337/diab.22.1.1)

28 Robertson RP, Halter JB \& Porte D Jr. A role for $\alpha$-adrenergic receptors in abnormal insulin secretion in diabetes mellitus. Journal of Clinical Investigation 197657 791-795. (doi:10.1172/JCI108338)

29 Ahren B. Autonomic regulation of islet hormone secretionimplications for health and disease. Diabetologia 200043 393-410. (doi:10.1007/s001250051322)

30 Kurose T, Seino Y, Nishi S, Tsuji K, Taminato T, Tsuda K \& Imura H. Mechanism of sympathetic neural regulation of insulin, somatostatin, and glucagon secretion. American Journal of Physiology 1990258 E220-E227.

31 Eikelis N, Schlaich M, Aggarwal A, Kaye D \& Esler M. Interactions between leptin and the human sympathetic nervous system. Hypertension 200341 1072-1079. (doi:10.1161/01.HYP.0000066289.17754.49)
Received 30 January 2015

Revised 20 May 2015

Accepted 1 June 2015 